\title{
Current landscapes and legacies of land-use past: Understanding the distribution of juvenile coho salmon (Oncorhynchus kisutch) and their habitats along the Oregon Coast, USA
}

\begin{tabular}{|r|l|}
\hline Journal: & Canadian Journal of Fisheries and Aquatic Sciences \\
\hline Manuscript ID & cjfas-2015-0589.R2 \\
\hline Manuscript Type: & Article \\
\hline Date Submitted by the Author: & 24-Jun-2016 \\
\hline Complete List of Authors: & $\begin{array}{l}\text { Steel, E. Ashley; USDA Forest Service, PNW Research Station, Statistics } \\
\text { Muldoon, Ariel; Oregon State University, College of Forestry } \\
\text { Flitcroft, Rebecca; USDA Forest Service, Pacific Northwest Research Station } \\
\text { Firman, Julie; Oregon Department of Fish and Wildlife } \\
\text { Anlauf-Dunn, Kara; Oregon Department of Fish and Wildlife, Aquatic } \\
\text { Inventories Project } \\
\text { Burnett, Kelly; USDA Forest Service, PNW Research Station } \\
\text { Danehy, Robert J.; NCASI - National Council for Air and Stream } \\
\text { Improvement, }\end{array}$ \\
\hline Keyword: & land ownership, salmonids, intrinsic potential, splash-dams, history \\
\hline \multicolumn{2}{|c}{} \\
\hline
\end{tabular}


Steel et al. - Landscapes and juvenile coho salmon

Current landscapes and legacies of land-use past: Understanding the distribution of juvenile coho salmon (Oncorhynchus kisutch) and their habitats along the Oregon Coast, USA

E. Ashley. Steel ${ }^{1}$, Ariel Muldoon ${ }^{2}$, Rebecca L. Flitcroft ${ }^{3}$, Julie C. Firman ${ }^{4}$, Kara J. Anlauf-Dunn ${ }^{4}$, Kelly M. Burnett ${ }^{3}$, Robert J. Danehy ${ }^{5}$

$11{ }^{1}$ PNW Research Station, USDA Forest Service, 400 N $34^{\text {th }}$ Street, Suite 201, Seattle, WA 1298103

$13{ }^{2}$ College of Forestry, Oregon State University, 321 Richardson Hall, Corvallis, Oregon 97331

$14 \quad \mathrm{USA}^{3}$ PNW Research Station, USDA Forest Service, 3200 SW Jefferson Way, Corvallis, OR, $15 \quad 97331$

$16{ }^{4}$ Corvallis Research Laboratory, Oregon Department of Fish and Wildlife, 28655 Hwy. 34, 17 Corvallis, OR 97333

$18{ }^{5}$ National Council for Air and Stream Improvement, $720 \mathrm{SW} 44^{\text {th }}$ Street, Corvallis, OR 97333

$21 \quad{ }^{1}$ Corresponding author: 206-732-7823 (p), 206-732-7801 (f), asteel@fs.fed.us 


\section{Abstract}

23 The Oregon Coastal landscape has a high degree of spatial structure with respect to landscape

24 characteristics such as air temperature, precipitation, and geology. Despite this underlying

25 structure, we found that a suite of immutable or intrinsic attributes, e.g. reach gradient, drainage

26 area, mean elevation of the catchment, and percent weak rock geology of the watersheds draining

27 to each of our 423 study reaches, could explain much of the variation in pool surface area across

28 the landscape and could contribute to an estimate of how many juvenile coho salmon

29 (Oncorhynchus kisutch) one might expect to find in those pools. Further, we found evidence of

30 differences in pool surface area across land ownership categories that reflect differing

31 management histories. Our results suggest that historic land and river management activities, in

32 particular log drives that occurred at least 50 years ago, continue to influence the distribution of

33 juvenile coho salmon and their habitats today.

34

35 Key Words: land ownership, landscape-scale, salmonids, intrinsic potential, splash-dams 
Steel et al. - Landscapes and juvenile coho salmon

\section{Introduction}

Understanding the distribution of instream habitats and the density of fish within those habitats is essential for effective watershed management and conservation of depressed fisheries populations. For wide-ranging species with a complex life history, such as Pacific salmon, untangling these relationships is particularly challenging. Field data describing instream habitats are generally only available over a small fraction of a species range; occupied habitat types may differ by life stage; and, even within a particular habitat type, suitability and capacity rarely remain constant over time. Landscape-scale studies, based on the conceptual model that natural features and human impacts across watersheds drive instream habitat conditions which in turn regulate, at least to some degree, salmon distribution and productivity, have been relatively successful at predicting adult spawners for coho salmon (Steel et al. 2012; Pess et al. 2002), Chinook salmon (Feist et al. 2003), and steelhead (Steel et al. 2004). Juvenile salmonids and their habitats, however, have rarely been evaluated at the landscape scale. Processes driving the distribution of juveniles and their habitats cannot be inferred from studies of spawning habitats or adults alone (Flitcroft et al. 2012; Gresswell et al. 2006), as juveniles do not simply rear in the same habitats in which they emerged from the spawning gravel. Juvenile salmonids often move over fairly long distances to occupy a separate habitat niche that is likely driven by different suites of natural conditions and is uniquely impacted by human activities. A better understanding of the location and condition of juvenile coho salmon habitats and of juvenile coho density within freshwater streams can contribute to improved restoration and conservation planning as well as a more holistic and detailed conceptual model of the relationship between landscape drivers, instream conditions, and coho salmon during the freshwater phases of their life-cycle. 
Steel et al. - Landscapes and juvenile coho salmon

Listed as threatened under the Endangered Species Act (ESA) (Weitkamp et al. 1995),

60

61

62

63

64

65

66

67

68

69

70

71

72

73

74

75

76

77

78

79

80

81

coho salmon (Oncorhynchus kisutch) along the Oregon Coast inhabit two distinct freshwater

habitat types over their three-year lifespan. Adults spawn in riffles and runs within low gradient, gravel-based rivers; juvenile coho salmon rear in deep pool habitats during summer and may redistribute into pools in more off-channel habitats with the onset of the fall rains (Sandercock 1991). Combinations of land use, land ownership, geology, and climate have repeatedly been successful at describing and predicting the distribution of adult coho across the landscape (Pess et al. 2002; Firman et al. 2011; Steel et al. 2012). Peak spawner counts within the Oregon Coast were highest in reaches draining forest land with little area in weak rock types, low densities of cattle and roads, less agriculture, gentle stream gradients, and relatively large fluctuations in winter temperature (Firman et al. 2011; Steel et al. 2012). However, adult coho salmon densities are only part of the story. When escapement is adequate, the availability of high quality winter pool habitat for juveniles is thought to limit coho salmon smolt production along the Oregon Coast (Nickelson et al. 1992; Solazzi et al. 2000). Landscape-scale studies have evidence that these habitat features associated with high quality juvenile habitat can be influenced by human activities such tree harvest and road building across watersheds. Pool density and large wood volume were strongly influenced by these land management descriptors in the Oregon Coast after accounting for natural landscape attributes such as gradient and geology (Anlauf et al. 2011).

River landscape analyses have been proliferating, effectively describing useful patterns and making predictions about where on the landscape particular species or habitats are likely to be found (Allan 2004; Steel et al. 2010; Johnson and Host 2010). Yet, untangling anthropogenic impacts from the intrinsic suitability of river reaches to support high quality coho salmon habitat 
Steel et al. - Landscapes and juvenile coho salmon

82 as defined by natural features is a challenge. Across the Oregon Coast, a high level of covariation

83 between natural landscape gradients (e.g. land form, climate and geology), and human activities

84 (e.g. forest management), hinders the interpretation of statistical models and our ability to

85 establish causal linkages between landscape-scale variables and fish (Lucero et al. 2011). In evaluating landscapes, we need to be able to differentiate between the potential of a site given

87 those factors that humans cannot reasonably change (intrinsic / immutable factors) and the impact of human actions, both locally and across the watershed. One approach has been to develop an index or summary metric that describes a stream's ability to provide high-quality habitat in the absence of human impacts. Burnett et al. (2007) developed such an index of intrinsic potential (IP), based on three immutable factors, stream flow, valley constraint, and

92 stream gradient, for juvenile coho salmon on the Oregon Coast. By separating, mapping, and exploring immutable landscape features versus measures of human impacts, we can begin to

94 identify those streams which naturally do not support high quality juvenile habitat or large densities of juvenile coho salmon versus streams which are likely to support high quality juvenile habitat in the absence of human disturbance. This approach can theoretically identify streams

97 that fail to reach their potential in supporting high quality habitat or high densities of juvenile fish because of human modifications of the natural landscape yet the efficacy of this IP has yet to 99 be tested on empirical observations over large spatial extents.

101 land-use designations. Across the Oregon Coast, for example, there is a rich logging history that 102 includes removal of the primary forest and the transport of downed trees via the fluvial network 103 using log-drives and splash-damming to build up adequate water supply for moving logs 104 downstream. Splash damming and log drives were common across western Oregon from the 
Steel et al. - Landscapes and juvenile coho salmon

1880s through the 1950s (Miller 2010). Scouring from these activities has led to widespread stream simplification across the Pacific Northwest and evidence suggests that physical conditions in splash-dammed streams have yet to recover (Lichatowich 1999; Miller 2010; Sedell and Duval 1985; Dolloff 1996). Though no consistent record was kept of splash dams or $\log$ drives at the time, Miller (2010) used a combination of archival, historical aerial photograph and field searches to develop a geo-database of all known splash-dam sites and log drives in western Oregon. This comprehensive new resource enables investigation not only of effects of current land-management activities but also of the potential for legacies of past management activities across the Oregon Coast.

In this analysis, we quantify the ability of immutable features of the landscape to explain the observed distribution of pool habitats, on which juvenile coho salmon depend, and the observed density of juvenile coho salmon within those pools. We also evaluate whether the summary index of intrinsic potential (IP) (Burnett et al. 2007) adds additional information beyond our base immutable models. Further, we test whether we can detect effects of past land management or present land ownership on the distribution of pool surface area or on the density of juvenile coho within those pools after accounting for immutable landscape features. We initiate our analysis with a detailed exploration of the Oregon Coast to understand spatial gradients in landscape factors throughout the region and the nature of the expected co-variation between potential immutable and anthropogenic influences on habitat. Our work is novel in the blending of apriori knowledge and hypothesis testing, in our access to empirical data over a vast spatial extent, and in our consideration of both current land ownership and legacies of past management activities. Our results enable (a) a comparison of relationships between landscape features and pool surface area versus juvenile coho salmon density in pools; (b) an evaluation of 
Steel et al. - Landscapes and juvenile coho salmon

128 the degree to which immutable landscape characteristics and the summary index of intrinsic

129 potential (IP) describe the current distribution of pool surface area and of juvenile coho salmon

130 within these pools; and (c) tests of the degree to which current and past land management are

131 correlated with pool surface area and with the distribution of juvenile salmon in these habitats.

133 Methods

134 Study Area

All survey reaches in our analysis are within the Oregon Coastal Province (Fig. 1; 20,305

$\mathrm{km}^{2}$ ). This mountainous region is underlain primarily by marine sandstones and shales or by

137 basaltic volcanic rocks. Elevations range from 0 to $1250 \mathrm{~m}$, though most coho salmon habitat is

138 in areas of lower gradients and below $700 \mathrm{~m}$ (Burnett et al. 2007). The temperate, maritime

139 climate provides mild, wet winters and dry summers. Base flows predominate in late summer;

140 peak flows occur in the fall following storm events.

The upland portion of the study area is dominated by coniferous forests with western red

142 cedar (Thuja plicata) and big leaf maple (Acer macrophyllum) in riparian areas. Current

143 disturbance regimes are driven by land use (including timber harvest, road building, and

144 agriculture) and fire suppression. Disturbance legacies that potentially continue to influence

145 upslope and riparian habitats include historic timber harvest activities, splash damming, log

146 drives, and infrequent but intense wildfires and windstorms (Franklin and Dyrness 1988). Most

147 of the current forestland is relatively young and the larger river valleys have been cleared for

148 agriculture (Ohmann and Gregory 2002). The majority of the land is privately owned; about a

149 third of the land is publicly owned (Spies et al. 2007).

150 Coho salmon in the study region belong to the Oregon Coastal Coho Evolutionarily 
Steel et al. - Landscapes and juvenile coho salmon

151 Significant Unit (ESU) (Weitkamp et al. 1995). In addition to coho salmon, four other salmonid

152 species reside in the study area: coastal cutthroat trout $(O$. clarki), Chinook salmon $(O$.

153 tschawytscha), chum salmon (O. keta), and steelhead (O. mykiss).

154

155

Pool and coho salmon data

156

The Oregon Plan for Salmon and Watersheds (http://nrimp.dfw.state.or.us/OregonPlan/)

157 defines the State of Oregon's system for monitoring instream habitat and coho salmon, including

158 both the juvenile and adult life stages, through a probabilistic sampling design of available

159 stream reaches (generalized random tessellation stratified (GRTS) design) (Stevens 2002). Using

160

the 1:24,000-scale high-resolution USGS NHD (http://nhd.usgs.gov/) drainage network, streams

161 and rivers have been attributed according to the current, known distribution of coho salmon and

162 steelhead trout; a random sample of these reaches was chosen for monitoring. A portion of sites

163 are visited annually, while the majority are resurveyed based on a rotating panel design of 3 and

1649 years, meant to coincide with the 3-year life cycle of coho salmon. The design is intended to

165 balance the need to estimate population abundance in each year (for which precision improves by

166 sampling more reaches within a year) and the need to detect trends over time (for which power

167 improves by revisiting the same reaches year after year) (Larsen et al. 2001; Larsen et al. 2004).

168 Our dataset included two potential response variables: pool surface area within a reach

169 and juvenile coho salmon counts within pools. We used all available data for $1^{\text {st }}$ through $4^{\text {th }}$

170 order streams within the distribution of coho salmon except for a few observations collected in

171 basins dominated by Siltcoos, Tahkenitch, and Tenmile Lakes or from reaches shorter than 0.6

$172 \mathrm{~km}$. Our final dataset contained a total of 1118 individual observations collected over 16 years

173 (1998 through 2013) at 423 reaches within $3246^{\text {th }}$ field HU's, referred to as "catchments" for 
Steel et al. - Landscapes and juvenile coho salmon

174 modeling purposes. Individual reaches ranged in length from $241 \mathrm{~m}$ to $1874 \mathrm{~m}$ with the majority

175 between $600 \mathrm{~m}$ and $1200 \mathrm{~m}$. Each was visited between 1 and 16 times. Eleven reaches were

176 visited in all 16 years; 193 reaches were visited for 2 to 15 repeat surveys; and 219 reaches were

177 visited only once.

Pools within each reach were enumerated and measured to provide an estimate of total

179 pool surface area within each reach. All pools that had a max depth of $\geq 20 \mathrm{~cm}$ deep and were $\geq$

$1806 \mathrm{~m}^{2}$ in surface area were snorkeled to identify and enumerate juvenile coho salmon. Snorkel

181 surveys consisted of a single pass conducted during base flows in August - September. Juvenile

182 coho salmon are known to move least in summer (Nickelson et al. 1992; Kahler et al. 2001),

183 making the snorkel survey a "snapshot" of the abundance and distribution of fishes in the

184 surveyed reach. Pools were assessed for water clarity or quality, receiving a rating based on

185 visibility. To ensure data quality, only density of juvenile coho salmon from pools receiving the

186 higher visibility ratings ( $85-92 \%$ of all pools) were included in this analysis.

188 Landscape Data

189 We focused on a set of immutable landscape attributes identified as important predictors 190 of the distribution of coho salmon and their habitats in previous analyses of this region (Firman 191 et al. 2011; Anlauf et al. 2011; Steel et al. 2012) and of the nearby Snohomish River in

192 Washington State (Pess et al. 2002), e.g., precipitation, proportion of the watershed with weak or 193 sedimentary geology, gradient, and elevation (Table 1). We did not include mean annual flow 194 because available estimates at study reaches are modeled as a function of drainage area, already 195 included in our list of potential predictors. In descriptive follow-up analyses to understand 
Steel et al. - Landscapes and juvenile coho salmon

differences across land ownership categories, we also employed a descriptor of forest cover at the landscape scale, the proportion of watershed dominated by large conifers (Table 1).

We summarized landscape characteristics relevant to each survey reach across the entire drainage area or watershed of each reach. Drainage area was defined as the area draining to the downstream end of the reach. To quantify landscape predictor variables within each watershed, we calculated the proportion of the total watershed in each category for categorical variables (i.e. geology, land ownership) (Table 1). Land ownership was included as an index of management history. USFS lands have been managed for a combination of goals including timber harvest, old growth forest conservation, wildlife habitat, fish habitat, water quality, and recreation (USDA Forest Service 1990). Management of BLM lands is also intended to balance a variety of uses including energy development, livestock grazing, recreation, timber harvest and protection of natural, cultural, and historical resources (http://www.blm.gov/wo/st/en/info/About_BLM.html). Private industrial forest lands, on the other hand, are, presumably, managed for long-term, sustainable timber production. Private nonindustrial forest lands include multiple management objectives across diverse ownerships. These private non-industrial forest (PrivateNI) lands, while nearly half forested, also include a large amount of agricultural land-use, residential development, and even a small amount of urban development. For continuous variables (i.e. air temperature), we calculated the area-weighted mean to provide an indication of average conditions over the entire watershed.

For each surveyed reach, we calculated the length-weighted average of intrinsic potential (IP) for coho salmon (Burnett et al. 2007). To quantify total amount of high quality habitat available to juvenile coho salmon within each catchment, we also calculated total length of stream with intrinsic potential $>0.75$. We note that this variable (LengthHighIP) was missing for 
Steel et al. - Landscapes and juvenile coho salmon

219

220

221

222

223

224

225

226

227

228

229

230

231

232

three reaches and so the three reaches were excluded from models testing for the statistical significance of this variable. Inputs used to calculate coho salmon IP were previously estimated from field data and 10-m digital elevation models (DEMs) (Clarke et al. 2008).

\section{Habitat data}

Habitat data to further explore observed relationships between ownership and juvenile coho salmon and their habitats were available because they were collected as part of the coastwide, integrated monitoring described above. In this analysis, we explored average values (1998 thru 2013) of three habitat variables: percent gravel, wood volume $\left(\mathrm{m}^{3}\right)$, and percent channel shade. These three habitat characteristics, surveyed mid-June to late September, were included because they are both important to juvenile coho salmon habitat and were found to be particularly sensitive to land management actions (Anlauf et al. 2011). Gravel is the estimated proportion of the stream-bed area that is classified as gravel $(2-64 \mathrm{~mm})$; it is quantified ocularly in the field. Wood volume is the volume of in-stream wood per $100 \mathrm{~m}$ of reach length $\left(\mathrm{m}^{3}\right.$ per $100 \mathrm{~m}$ ); it includes all pieces of wood that are within the active channel and are $\geq 0.15 \mathrm{~m}$ in DBH and $\geq 3 \mathrm{~m}$ in length. Percent channel shade is the percentage of the stream channel that is shaded; it is collected on both the left and right sides of the stream using a clinometer. All three habitat variables were collected by habitat unit (e.g. riffle, pool) and summarized by reach. For further field details, see Moore et al. (2007).

\section{Statistical Methods}

Data analysis was completed in five steps. (1) We first conducted extensive exploratory and graphical analysis to understand and display the spatial distribution of each potential predictor 
242 and the relationships between potential predictors of pool distribution and of juvenile coho

243 salmon within pools across the landscape. (2) In our second step, we developed a base model of

244 pool surface area as a function of immutable landscape features found to be important for

245 predicting pool habitat in previous work. At this stage, we did not consider anthropogenic

246 impacts. (3) Third, we built a similar base model of fish density within pool habitat. The

247 juvenile coho base model used a similar collection of immutable variables found to be important

248 for predicting coho salmon habitat in previous work. With these two base models, we examine

249 how well our suite of immutable landscape variables explains observed spatial variation in pool

250 surface area or in juvenile coho salmon density. The two models form the basis for follow-up

251 analyses that test for additional explanatory power of our key variables of interest given the

252 landscape context of each site. Note that we did not conduct any statistical hypothesis tests or

253 variable selection to develop these base models. Inclusion of variables was based on our

254 ecological knowledge and past published analyses describing linkages between landscapes and

255 habitat characteristics that support coho salmon. (4) In our fourth step, we used these two base

256 models as the foundation for formal statistical hypothesis testing to detect effects of suites of key

257 variables of interest describing: (a) intrinsic potential (IP), (b) land ownership, and (c) legacies of

258 land-use past on both pool habitat and density of juvenile coho salmon within pools. (5) In the

259 final step of our analysis, we introduce habitat data from Anlauf et al. (2011) to explore whether

260 instream habitat conditions can explain observed relationships between land ownership and pool

261 surface area.

263 (1) Landscape structure. To best understand landscape structure, we conducted extensive

264 exploratory analyses including correlation tables, spatial maps, and boxplots comparing the 
Steel et al. - Landscapes and juvenile coho salmon

265

266

267

268

269

270

271

272

273

274

275

276

277

278

279

280

281

282

283

284

285

286

287

distribution of predictor variables across categories of, for example, land ownership. Given the challenges of conducting analyses over large extents without true replication or control, the goal of these exploratory analyses was to understand the underlying relationships that might cloud our ability to interpret statistical models. We focused on relationships that concerned the spatial distribution of variables about which we planned to conduct formal hypothesis tests (intrinsic potential, land ownership, and legacies of land-use past, e.g. splash dams and log-drives).

\section{(2) Base model for pool surface area. A linear mixed model was built using the natural logarithm} of pool surface area $\left(\mathrm{m}^{2}\right)$ as the response and survey year, catchment, reach, and the catchment by year interaction as random effects. Catchment was included as a random effect because, in some cases, there were 2 to 4 reaches within one catchment.

We based our model of pool surface area on the work in Anlauf et al. (2011). They were able to describe pools per $100 \mathrm{~m}$ using five immutable variables: reach gradient, drainage area, mean elevation of the catchment, flow (cfs), and percent weak rock geology in the catchment. We wanted to account for these relationships with immutable variables before testing our key variables of interest. As explained above, we eliminated flow from our pool surface area model because it is generally estimated from drainage area; therefore, these variables are highly correlated. As in Anlauf et al. (2011), there appeared to be a linear relationship between the natural log of pool surface area and the natural log of drainage area. We used an updated geology layer and substituted percent sedimentary rock for the percent weak rock geology layer used in previous analyses. In our dataset, survey lengths varied considerably both across and, somewhat surprisingly, within reaches across years. Intuitively, pool surface area might depend on the survey length and so survey length was included in the model. 
Steel et al. - Landscapes and juvenile coho salmon

The base model of $\ln ($ pool surface area) contained gradient $(\%)$, elevation $(\mathrm{m})$,

$\ln ($ drainage area), percent sedimentary rock in the catchment, and survey length as fixed effects.

Residuals were checked for temporal and spatial autocorrelation using autocorrelation function

291

292

293

294

295

296

297

298

299

300

301

302

303

304

305

306

307

308

309

310

(3) Base model for juvenile coho salmon counts. Juvenile coho salmon count data were analyzed with a generalized linear mixed model (GLMM) using a Poisson distribution with a natural logarithm link. Because the amount of pool habitat varied by reach and year, total pool surface area $\left(\mathrm{m}^{2}\right)$ was used as an offset. Survey year, catchment, reach, and the catchment by year interaction were included in the model as random effects. To account for overdispersion (extra-Poisson variation), the observation-level random effect represented by the reach by year interaction was also included as a random effect.

Our model of juvenile coho salmon counts was based on the suite of variables that appeared in the "best" habitat models in Anlauf et al. (2011) to predict a wide range of habitat conditions from instream wood to pool complexity. The seven variables were precipitation in the catchment, percent intermediate sedimentary rock in the catchment, reach gradient (\%), drainage area $\left(\mathrm{km}^{2}\right)$, elevation $(\mathrm{m})$, flow (cfs), and percent weak rock in the catchment. Again we eliminated flow due to high correlation with drainage area and we substituted sedimentary rock for "weak geology" and "intermediate sedimentary rock", therefore the model had six variables. Because we expect that habitat conditions, at least to some degree, drive juvenile coho salmon numbers, we wanted to account for variation explained by these immutable variables 
Steel et al. - Landscapes and juvenile coho salmon

311 before testing for relationships between juvenile coho salmon numbers and the key variables of

312

313

315

316

317

318

319

320

321

322

323

324

325

326

327

328

329

330

331

332

333

\section{(4) Statistical tests for intrinsic potential, land ownership, and legacies of land-use past}

We tested for a relationship between either pool surface area or juvenile coho salmon counts and each of the key variables of interest. The first variable of interest was intrinsic potential (IP) which was measured in two ways: (a) the length weighted average of IP and (b) the total length of habitat with high intrinsic potential $(>0.75)$ in the catchment. We also note that there were 3 missing values for high IP; tests for high IP were computed on a dataset that did not include these three study reaches. The second variable of interest was land ownership. We included land ownership as (a) proportion public ownership in the catchment; (b) the proportion private ownership used for industrial forestry (PI); (c) the proportion private ownership not used for industrial forestry (PrivateNI). To better understand land ownership patterns, we also overlaid the ownership classification with an existing land-use data layer (Burnett et al. 2007) and summarized land-use by ownership category. Finally, we were interested in the potential legacy of past land-uses including (a) counts of past splash dams in the catchment and (b) length of historical log drives in the catchment. 
Steel et al. - Landscapes and juvenile coho salmon

To test for a relationship with either pool surface area or number of juvenile coho salmon, these variables were added one-by-one to the base model. All test results are for each variable when added alone to the base model. The one exception was intrinsic potential (IP). Because IP is a summary index that includes gradient, it was tested against the full immutable model including gradient as well as against the immutable model without gradient. Tests of coefficients when key variables were added to the base pool surface area model were conditional F-tests using the Kenward-Roger degrees of freedom correction (Kenward and Roger 1997). Tests of coefficients when key variables were added to the base juvenile coho salmon model were 1 degree of freedom $\chi^{2}$ likelihood ratio tests. Reported confidence intervals of coefficients are $95 \%$ profile likelihood confidence intervals. Effect sizes are presented as the change in $\ln$ (pool surface area) or in the number of juvenile coho salmon for a change of approximately $10 \%$ of the observed range in each variable.

\section{(5) Land ownership and instream habitat}

To observe possible differences in instream conditions or attributes of high quality forest habitat across land-ownership categories, we graphically compared the distribution of these instream habitat variables; \% gravel, \% shade and large wood volume, across land-ownership categories. To evaluate terrestrial condition, we estimated the percent of the watershed with very large conifers (Table 1) across four classes of land ownership: private (non-industrial and industrial) and public (USFS and BLM).

\section{Results}

(1) Landscape structure. Spatial pattern appears in most of the potential predictors of pool 
Steel et al. - Landscapes and juvenile coho salmon

357 habitat and juvenile coho salmon (Fig. 2). For example, study reaches draining catchments with

358 large annual ranges in air temperature (TempRange) were found in the southeastern parts of the study area and those with high mean annual precipitation (Precip) were found in the northwestern portion of the study area. Study reaches draining catchments with high proportions of sedimentary geology (Sedimentary) were more prevalent in the southern parts of the study area and the northern tip. Log drives (LogDrives) and splash dams (SplashDams) appear to have occurred predominantly in the southern portions of the study landscape. Intrinsic potential (AvgIP and LengthHighIP) are mildly clustered but occur across the entire study area. Land ownership was not distributed evenly across the study area (Fig. 2). Study reaches draining catchments with the highest proportion of big tree cover (BigTrees) occurred in one large cluster 367 along the west coast of the study area, coincident with high amounts of public land (Fig. 2). A closer inspection of the distribution of study reaches draining catchments with particular public (BLM, USFS) and private (non-industrial and industrial) land ownership reveals further landscape structure with the study reaches. Those draining catchments with higher

371 proportion of USFS land are located in two large clusters in the middle of the study region, study

372 reaches draining catchments with high proportions of private industrial (PrivateInd) lands are

373 located in clear bands, and private non-industrial (PrivateNI) lands concentrated along the coast

374 (Fig. 3). The uneven distribution of land ownership could also be observed in differences

375 between the distribution of immutable landscape variables describing areas with relatively high

376 versus relatively low ownership in each of three ownership categories, BLM, USFS, and private

377 (Fig. 4). For example, the elevation range was wider for catchments with high proportions of

378 land managed by the USFS. Areas with more land in private non-industrial use were generally at

379 lower elevations, had lower stream gradients, and high average intrinsic potential scores. In 
Steel et al. - Landscapes and juvenile coho salmon

380

381

382

383

384

385

386

387

388

389

390

391

392

393

394

395

396

397

398

399

400

401

402

summary, we observe that the lands under different ownership classes are intrinsically different with respect to several key variables.

(2) Pool surface area. The base model for $\ln ($ total pool surface area) included gradient, elevation, $\ln ($ drainage area), survey length, and sedimentary geology (Table 2). Marginal pseudo- $\mathrm{R}^{2}$ for this linear model was 0.632 . The majority of the variance was at the reach level (0.429) with a smaller amount of variance at the catchment level (0.141). Graphical assessment of residuals indicated that the base pool surface area model did not have serious problems with temporal autocorrelation; however there was some spatial autocorrelation primarily in the E-W direction. Such anisotropic spatial autocorrelation may be difficult to eliminate as the rivers run from the coast range to the ocean in a more or less east to west orientation. As might be expected, there was very little overall annual variation in pool surface area (0.021). Unexplained catchment by year, and reach by year (residual) variability were relatively high $(0.203$ and 0.106 respectively).

(3) Juvenile coho density. The marginal pseudo- $\mathrm{R}^{2}$ for this Poisson model with a log link including precipitation, sedimentary geology, gradient, gradient ${ }^{2}$, elevation, and drainage area was 0.338 (Table 3 ). The residuals from the base model did not appear to have any problems with temporal or spatial autocorrelation. A relatively large amount of the variance (2.665) is the distribution-specific variance (on the link scale) due to the variance of the Poisson distribution being based on the mean; a Poisson GLMM will have this distribution-specific variance and so it is important to remember that the pseudo- $\mathrm{R}^{2}$ could never become 1 (Nakagawa and Schielzeth 2013). There was a large amount of unexplained variance at the catchment scale (2.437) and at 
Steel et al. - Landscapes and juvenile coho salmon

403 the reach scale (1.497). There was relatively less annual variance in juvenile coho counts

404 (0.443). There was also unexplained variability for catchment by year (1.409), and reach by 405 year (residual) (0.225).

406

407

(4) Statistical tests for intrinsic potential, land ownership, and legacies of land-use past

408 Intrinsic potential. Mean intrinsic potential (IP) provided only minor additional explanatory 409 power beyond that of gradient for pool surface area $(\mathrm{p}=0.093)$ and no additional explanatory

410 power for fish density in pools. There was a large and positive statistically significant effect of 411 average intrinsic potential when gradient was removed from the model (Table 4, Fig. 5). The

412 length of high intrinsic potential habitat (LengthHighIP ) had a statistically significant effect on 413 pool surface area but not on the number of juvenile coho salmon (Table 4). We caution that 414 although the coefficient describing the effect of total length of high intrinsic potential is negative 415 (suggesting that study reaches in catchments with longer lengths of river estimated as high 416 intrinsic potential have lower pool surface areas), it is difficult or impossible to untangle the 417 effect of one predictor variable entered in a model that already contains so many similar and 418 potentially collinear variables.

Land ownership. There was a statistically significant positive effect of public ownership on pool 421 surface area (Table 4, Fig. 5). In other words, after accounting for geology, elevation, gradient, 422 and drainage area, reaches with a higher percentage of the catchment in public ownership had a 423 larger pool surface area. In reverse, we saw that reaches with a higher proportion of private 424 ownership and, in particular, private ownership that was classified as not industrial forestry, had 425 smaller pool surface areas. For a better understanding of the distribution between private 
Steel et al. - Landscapes and juvenile coho salmon

426 industrial forestry and private non-industrial forestry, we compared the ownership classification

427 to the existing land-use data layer (Burnett et al. 2007) and found that private industrial lands

428 (PrivateInd) were composed of just over 98\% forest lands. Private non-industrial lands

429 (PrivateNI) represent a composition of urban (5.4\%), residential (14.4\%), agriculture (29.7\%), 430 forest (46.3\%), and other uses (4.1\%).

431

432 Legacies of land-use past. The density of reaches with historical log drives in the catchment was

433 not statistically significant in either model though there were indications that log drive length

434 may have a negative effect on pool surface area $(\mathrm{p}=0.109)$. However, we did see a statistically

435 significant effect of splash dam presence versus absence in the watershed of the study reach on

436 juvenile coho salmon density $(\mathrm{p}=0.049)$. The effect of splash dam presence on juvenile coho

437 salmon density was fairly large, one splash dam is estimated to increase juvenile coho salmon

438 density by an estimated $139.5 \%$; however there was also a large amount of associated

439 uncertainty (95\% confidence interval equals 0.4 to $474.9 \%$ ) reflecting the relatively small

440 number of sites $(n=24)$ with splash dams present (Table 4).

441

442 (5) Land ownership and instream habitat. There was little qualitative difference in shade or

443 gravel across land ownership categories (Fig. 6). The distribution of instream wood volume was

444 somewhat reduced in the areas with greater than $30 \%$ private industrial (PrivateNI) ownership.

445 Reaches whose catchments drained areas with high proportions of public land were also those

446 whose catchments drained areas with high proportions of very large conifers. Note that big trees

447 did occur with distinct clusters. Throughout the study, the average proportion of a study

448 watershed in large trees was $16.7 \%$. More than $40 \%$ of the study reaches drained watersheds 
Steel et al. - Landscapes and juvenile coho salmon

449 with less than $10 \%$ of the area in big trees; only $2 \%$ of the study reaches drained watersheds

450 with more than $50 \%$ of the area in big trees.

451

\section{Discussion}

453 Given that there is a great deal of spatial structure in landscape-scale variables on the Oregon

454 Coast, untangling relationships between landscape features, in-stream habitat, and aquatic biota 455 is particularly important for effective management of aquatic resources. We found that pool 456 surface area, an essential element of coho salmon habitat can be described fairly well by

457 relatively immutable landform features: drainage area, elevation, geology, and gradient. A

458 similar set of immutable landform features also play a role, albeit a smaller role, in explaining

459 juvenile coho salmon density within pools. Building on these landscape models, we

460 corroborated the management relevance of the concept of "intrinsic potential", quantified

461 negative effects associated with private land ownership on pool surface area, and observed that

462 legacies of land-use past may continue to play a role in determining patterns of juvenile coho

463 salmon density across the landscape. By linking landscape-scale data on past and current land

464 management activities with a large dataset on the distribution of juvenile coho salmon and their

465 habitats, we provide insight into where on the landscape we might expect to find these fish and

466 how management of both terrestrial and aquatic ecosystems may have impacted their

467 distribution.

Spatial structure of the Oregon Coastal Landscape.

470 Landscape-scale approaches have been useful in informing management of freshwater fishes and

471 their habitats across a wide range of ecoregions (Steel et al. 2010) and yet the spatial structure of 
Steel et al. - Landscapes and juvenile coho salmon

472 landscape-scale data poses continuous challenges. To address these challenges, Lucero et al.

473 (2011) suggest that landscape-scale studies, particularly studies focusing on river systems, which

474 by nature are highly structured landscapes, follow a few principles: expect multicollinearity and

475 interpret any one particular landscape feature with caution; conduct thorough exploratory

476 analyses including maps of potential predictors; resist mechanistic or causal interpretations; and

477 resist extrapolation across regions.

In our exploratory analysis, we found, as expected, that immutable landscape features are

479 not distributed randomly across the Oregon Coast landscape nor have human impacts been

480 applied to the landscape at random. We observed strong spatial patterns in variables of interest,

481 both relatively immutable descriptors of the landscape and variables that reflect past and present

482 human impacts. These patterns can be as simple as "it is wetter in the north and the annual

483 range in air temperature tends to be higher at higher elevations" (Fig. 2). There are likely also

484 complex histories that are difficult to deduce from present day conditions. For example,

485 agriculture was likely initiated in floodplains by early settlers of the region as they were the

486 easiest to convert and had rich soils. These suitable conditions reflected a combination of

487 climate, geology, and landform; these same factors drive the distribution of suitable fish habitat

488 making it particularly challenging to untangle the effects of agriculture on fish distribution in

489 many basins. Lucero et al. (2011) found results similar to ours across the Oregon Coast. Of

490 course, the Oregon Coast is not the only region with considerable landscape structure. Looking

491 at 261 small watersheds across Idaho, Montana, Oregon, and Washington, Kershner et al. (2004)

492 noted that watersheds containing reference streams tended to be found at higher elevations,

493 receive more precipitation, and have a slightly higher percentage of federally-managed lands

494 than did managed watersheds. 
Steel et al. - Landscapes and juvenile coho salmon

We identified a few patterns across the Oregon Coast of particular importance for model

building and interpretation. First, there is a clear north-south gradient in terms of precipitation and geology. River basins in the southern parts of our study area have less rainfall and more

sedimentary rock (Fig. 2). Models that include these two variables may also include

information about other, unmeasured variables that vary longitudinally such as air temperature

or landslide susceptibility. Second, there is an east-west gradient from areas of higher elevation

with greater air temperature ranges and smaller streams with steeper stream gradients (not displayed) to lower-elevation, lower-gradient, wider streams (not displayed) that drain to the ocean along the coast. These sets of variables co-vary in predictable ways and, in fact, we were not able to eliminate all spatial covariance along this east-west gradient in our base model of

505 pool surface area. When any one of these variables is used in a model, information about the 506 others is also included by default. Third, land ownership is not distributed evenly across the 507 various parts of the study landscape. explaining the number of fish in pools

511 The distribution of pools across the landscape is relatively easy to model with landscape-level

512 predictors. Summer pool surface area varied across reaches but was relatively stable over time

513 within a particular reach; there wasn't a great deal of correspondence in pool surface area for

514 reaches within the same catchment; and the base model of pool surface area, using only

515 immutable landscape-scale variables, was able to explain a relatively large amount of the

516 variability in pool surface area. There remains, however, a relatively large amount of

517 unexplained variability in pool surface area for any particular reach. Previous correlative 
Steel et al. - Landscapes and juvenile coho salmon

518 research in this and in other basins has also identified relationships between similar landscape

519 features and the distribution of pool habitat (Burnett et al. 2006; Hicks and Hall 2003). Our

520 results also have a well-understood mechanistic interpretation. Pools are formed by scour

521 around obstructions such as large boulders and via inputs of large wood as well as where

522 relatively soft substrates are eroded by streams with adequate stream power, resulting from a

523 combination of flow and gradient (Buffington et al. 2002; Frissell et al. 1986; Hicks and Hall

524 2003; Montgomery et al. 1999; Wohl et al. 1993).

525 Landscape-level predictors do not explain the number of juvenile coho salmon within

526 pools as well as they explain pool distribution. There was high annual variability in juvenile

527 coho salmon counts within a particular reach or catchment and this annual variability made it

528 relatively more difficult to identify consistent relationships between fish density and landscape

529 features that do not change through time. If a site were visited in one year and then again in the

530 following year, we would not expect to see the same number of juvenile coho salmon; however,

531 given similar flow conditions, we would expect to observe about the same pool surface area.

532 Given that we could not include predictors that varied over time, we can expect our model of

533 juvenile coho salmon abundance to estimate the mean abundance over time and therefore to

534 explain less of the variation in the data than our model of pool surface area. We chose to model

535 pool habitat and juvenile coho salmon independently to untangle how intrinsic features of the

536 landscape drive these two responses and to test specific hypotheses about human impacts.

$537 \quad$ Future efforts may benefit from an exploration of time variable predictors, such as annual

538 flow, descriptors of other stages of the coho salmon life cycle, such counts of spawning adults,

539 and incorporation of spatial patterns on stream networks. We might expect, for example, that

540 observed relationships between juvenile coho salmon and landscape conditions depend on 
Steel et al. - Landscapes and juvenile coho salmon

541 population dynamics; when marine survival is low, adult returns are few, and the number of

542 resulting juveniles can be very low. In years with low levels of adult returns, we might expect

543 juvenile coho salmon to inhabit only the best habitats (Flitcroft 2007) and in years with higher

544 levels of adult returns we might expect juvenile coho salmon to expand into more marginal areas

545 (Flitcroft et al. 2014). Additionally, the proximity of adult and juvenile habitats or the network

546 distances between suitable seasonal habitats may also play a strong role in juvenile coho salmon

547 distribution (Flitcroft et al. 2012). The most productive habitats are likely to be where there is

548 both suitable habitat for adults to spawn and juvenile coho salmon to rear and overwinter

549 (Anlauf-Dunn et al. 2014).

Intrinsic attributes of a site are useful for explaining pool surface area

552 The concept behind a site's intrinsic potential is that some areas are naturally, or intrinsically,

553 more suitable as fish habitat. Burnett et al. (2007) defined the intrinsic potential (IP) of a site for

554 juvenile coho salmon as the geometric mean of normalized variables describing gradient, stream

555 flow, and valley constraint. In the absence of human impacts, sites with a high intrinsic

556 potential would be expected to support a larger number of fish than sites with low intrinsic

557 potential. IP has been used to provide a reasonable estimate of where on the landscape one

558 might expect to find juvenile coho salmon across streams in Coastal Oregon, the Willamette

559 River valley, and a part of the lower Columbia River basin where actual habitat conditions and

560 juvenile coho salmon distribution were unknown (Burnett et al. 2007). Flitcroft et al. (2014)

561 also found that the intrinsic potential of stream reaches was useful in understanding

562 distributional patterns of juvenile coho salmon.

563 Using 16 years of observed pool surface area from randomly selected sites across the 
Steel et al. - Landscapes and juvenile coho salmon

564 Oregon Coast, we also found that a similar suite of variables could describe the distribution of 565 pool surface area, the defining feature of juvenile coho salmon habitat in summer (Nickelson et

566 al. 1992). Like the Burnett et al. (2007) index, our model was strongly influenced by stream

567 gradient. We did not have access to localized flow observations but our model included drainage

568 area which is highly correlated with flow in most regions. Our model included elevation and

569 sedimentary geology which, in these basins, we would expect to describe a very similar concept

570 to that of valley confinement as used in Burnett et al. (2007). Not surprisingly, the average of

571 the Burnett et al. (2007) IP index contributed little to explaining variance in pool surface area in

572 models that already contained such a similar suite of landscape descriptors. When gradient was

573 removed from our landscape models, we found a large and statistically significant effect of

574 mean IP index (Burnett et al. 2007) on pool surface area as well as on the density of juvenile

575 coho salmon within those pools. Although gradient is clearly a primary driver of where on the

576 landscape pool habitat is likely to be found, the other features in IP, flow and valley constraint,

577 are also necessary for understanding pool habitats. In our model, IP showed a very weak

578 additional influence beyond gradient likely because our model also already contained elevation,

579 drainage area, and geology, all of which are highly correlated with valley constraint and mean

580 annual flow.

581 Our results provide further evidence that the concept of intrinsic potential, a combination

582 of relatively immutable landform features, is a useful management tool for understanding where

583 across the Oregon Coast we might expect to find juvenile coho salmon. Similar indices have

584 been used successfully for predicting the distribution of key habitat features for other salmonid

585 species and other life stages. Busch et al. (2013) used a combination of valley confinement,

586 stream width, and gradient to successfully identify potential Chinook salmon spawning habitat 
Steel et al. - Landscapes and juvenile coho salmon

587 in the nearby Lower Columbia River Basin. Bidlack et al. (2014) used mean annual flow, 588 gradient, and glacial influence to identify probable habitat for juvenile Chinook salmon across 589 the vast Copper River watershed, Alaska. Similar indices may, in fact, be useful for a wide 590 range of fishes across a wide range of geographies. Using 1,548 pan-European sample sites, 591 Logez et al. (2012) modeled the distribution of 21 common fish species and found that stream 592 power, a function of gradient and stream flow, was the only variable retained in the best model 593 for all 21 species. Intrinsic potential (Burnett et al. 2007) can also be used to estimate the quantity of available habitat that is potentially highly suitable (LengthHighIP). In our dataset, and in most situations, field data describing in-stream habitat conditions are only available for a subset of a basin or for a particular reach of interest. Therefore, the total length of stream habitat of highly suitable habitat available to migratory species cannot be calculated or estimated from on-theground observations. In our models, the quantity of available habitat that is potentially highly 600 suitable (LengthHighIP), total length of reaches within the catchment that have a high intrinsic

601 potential, improved our models of pool surface area even for a model that already included a 602 suite of landscape variables similar to those in the primary intrinsic potential index. The additional information provided by this metric was expected to be an estimate of the total 604 amount of high quality habitat potentially available to fish, regardless of basin size. We 605 hypothesize that, in addition to describing total habitat available to fish, LengthHighIP also 606 provides a general indication of the location and condition of the catchment surrounding the 607 study reach. 
610 Even after considering a set of basic immutable landscape characteristics, land ownership was an

611 important factor in explaining the amount of available pool habitat, the defining element of

612 juvenile coho salmon habitat (Fig. 5). Looking at the relative contributions of public, private

613 industrial, and private non-industrial ownership, we see that pool surface area was higher in areas

614 with higher proportions of public ownership and lower in areas with higher proportions of

615 private ownership. Furthermore, this negative effect was stronger for private lands not used for

616 industrial forestry (PrivateNI) than areas with high proportions of private industrial forestry

617 (PrivateInd). Similar results have been observed elsewhere. Looking at over 200 watersheds

618 distributed across the Columbia River Basin, Kershner et al. (2004) found that pools in

619 unmanaged watersheds tended to be deeper and to have fewer fine sediments in the pool tails as

620 compared to managed watersheds. As for most of our potential predictors, ownership did not

621 have a statistically significant effect on juvenile coho salmon density within pools.

One possible explanation for these results is that differences in aquatic conditions across land ownerships reflect the history of terrestrial and aquatic land management. In the nearby

624 Puget Sound region, trends in adult coho salmon over time were correlated with trends in forest

625 cover, and inversely correlated with urbanization (Bilby and Mollot 2008). Across 156

626 watersheds on Vancouver Island, Canada, just a bit further north, a legacy of current and historic

627 forest management, indicated by features such as forest fragmentation, no-forest cover, and early

628 successional forests, was the one landscape characteristic that had a generally negative effect on

629 anadromous salmon populations across species (Andrew and Wulder 2011).

631 investigation. The first consideration is the underlying correlation between land ownership and

632 topography; for example, high elevation lands are much more likely to be managed by the USFS 
Steel et al. - Landscapes and juvenile coho salmon

633 than to be in non-industrial private ownership. The history of ownership combined with natural

634 landscape patterns has led to the highly structured nature of the Oregon Coastal landscape as

635 described above. Testing for the effect of ownership only after incorporating the effects of

636 various immutable landscape features can account for some of the unbalanced and co-varying

637 spatial patterns but cannot eliminate the issue. As such, our analysis cannot be interpreted as a

638 causal relationship between ownership and pool habitat. Rather, our results show that differences

639 in the amount of pools differs by ownership.

640

\section{Legacies of past human activities persist}

642 Although the practice of log drives and splash damming streams and rivers ended over fifty years 643 ago, we observed an effect on current stream habitat conditions. The length of stream affected 644 by log drives was associated with a reduction in pool area even after accounting for landscape 645 configuration, and there is a potentially large effect of splash damming on the number of juvenile 646 coho salmon observed within a reach. In the few reaches where splash dams were present, we 647 observed an over $100 \%$ increase in juvenile coho salmon given available pool habitat. The 648 evidence is not particularly strong due to a small sample size and variable data, but the potential 649 effect size is large (Table 4). Although our landscape-scale models were not able to detect an 650 effect of splash dams on pool surface area, Miller (2010) found there to be fewer deep pools in 651 reaches affected by splash dams and significantly more exposed bedrock (by isolating the effects 652 of splash dams through upstream downstream comparisons). In combination, our results suggest 653 that log drives and splash dams reduced pool surface area leaving juvenile coho salmon to be 654 present at much higher densities than might otherwise be expected in the remaining pool habitat.

655 Current and future fish habitat assessments will benefit from knowledge of these and other 
Steel et al. - Landscapes and juvenile coho salmon

656 disturbance legacies.

657

658

659

660

661

662

663

664

665

666

667

668

669

670

671

672

673

674 675 watershed in big trees. Effects of forest harvest on instream habitats and, in particular, on pool

676

677

678

\section{Land ownership and current habitat conditions}

Ignoring the spatial structure of the data and simply comparing the distribution of various immutable variables across areas with high and low (relatively) proportions of ownership classes, we can again see that ownership was not assigned randomly (Figure 4). Areas with high proportions of private non-industrial lands are at lower elevations, have lower stream gradients, somewhat larger drainage areas, and therefore somewhat higher average intrinsic potential.

These streams are in downstream coastal areas that should have large amounts of pool habitat. After accounting for immutable variables to the best of our ability, we observed that reaches draining watersheds with higher amounts of private non-industrial lands have lower pool surface areas (Table 4, Figure 5).

To further explore the relationship between ownership, land management, and pool habitat, we considered whether in-stream or terrestrial habitat conditions were also different in reaches draining watersheds under different ownerships. We observed a potential reduction in wood volume for sites in private non-industrial ownership and large differences in the proportion of a watershed with large trees between public and private ownership (Figure 6) suggesting an additional legacy of timber harvest and development on the landscape; public lands have retained more big trees (Fig. 6). Few sites in private ownership maintained more than $30 \%$ of the distribution, are well-known. For example, clearcutting without riparian buffers has been associated with reduced pool areas in Alaskan streams (Heifetz et al. 2011). A meta-analysis of effects of riparian harvest across many published studies found reductions in pool size, 
Steel et al. - Landscapes and juvenile coho salmon

679 frequently associated with stream cleaning, following logging across a wide variety of stream 680 sizes and stream gradients (Mellina and Hinch 2009). We note, however, that public forests are 681 still relatively young with nearly all sites having less than $50 \%$ of the watershed in big trees. 682 Given the 150-250 years required for stream adjacent forests to approach pre-harvest function 683 (Bilby et al. 2003), present day forests across our sites, distributed throughout the Coast Range, 684 rarely achieve this goal.

\section{Management Implications}

687 Despite the high degree of spatial structure across the Oregon Coastal landscape, we found that 688 the immutable or intrinsic landscape attributes of a particular site can provide a good 689 understanding of the distribution of pool surface area and can contribute to an understanding of

690 juvenile coho salmon distribution within these pools. Where on-the-ground observations are 691 lacking, estimates based on immutable features or IP can provide managers with information for 692 identifying and prioritizing restoration and conservation opportunities. Comparisons between 693 empirical observations and estimates based on immutable landscape features can suggest where 694 streams are failing to reach their potential in supporting high quality habitat or high densities of 695 juveniles, providing a foundation on which to quantify and understand human effects on the 696 landscape. We found fairly strong evidence of differences in pool surface area across lands with 697 varying current ownership and therefore differing management histories. Further, we found 698 evidence that historic land and river management activities, in particular log drives that occurred 699 at least 50 years ago, continue to influence the distribution of juvenile coho salmon and their 700 habitats today. 
Steel et al. - Landscapes and juvenile coho salmon

701 Acknowlegements

702 We thank Kelly Christiansen for extensive help with spatial databases and the creation of Figure

703 1. We also thank Dr. Dana Infante, Michigan State University, for a particularly helpful

704 manuscript review. This work was supported by the National Council for Air and Stream

705 Improvement (NCASI) and the USDA Forest Service's Pacific Northwest Research Station. 
Steel et al. - Landscapes and juvenile coho salmon

706

707

708

709

710

711

712

713

714

715

716

717

718

719

720

721

722

723

724

725

726

\section{References}

Allan, J.D. 2004. Landscapes and riverscapes: The influence of land use on stream ecosystems. Annual Review of Ecology Evolution and Systematics 35: 257-284.

Andrew, M.E., and M.A. Wulder. 2011. Idiosyncratic responses of Pacific salmon species to land cover, fragmentation, and scale. Ecography 34: 780-797.

Anlauf, K.J., Jensen, D.W., Burnett, K.M., Steel, E.A., Christiansen, K., Firman, J.C., Feist, B.E. and Larsen, D.P. 2011. Explaining spatial variability in stream habitats using both natural and management-influenced landscape predictors. Aquatic Conservation: Marine and Freshwater Ecosystems 21: 704-714.

Anlauf-Dunn, K.J, Ward, E.J., Strickland, M., and Jones, K. 2014. Habitat connectivity, complexity, and quality: predicting adult coho salmon occupancy and abundance. Can. J. Fish. Aquat. Sci.71(12): 1864-1876.

Bidlack, A.L., Benda, L.E., Miewald, T., Reeves, G.H., and McMahan, G. 2014. Identifying suitable habitat for Chinook salmon across a large, glaciated watershed. Trans. Am. Fish. Soc. 143:689-699.

Bilby, R.E. and Mollot, L.A. 2008. Effect of changing land use patterns on the distribution of coho salmon (Oncorhynchus kisutch) in the Puget Sound region. Can. J. Fish. Aquat. Sci. 65: $2138-2148$.

Bilby R, Reeves G, Doloff C. 2003. Sources of variability in aquatic ecosystems; factors controlling biotic production and diversity. In Strategies for Restoring River Ecosystems: Sources of Variability and Uncertainty in Natural and Managed Systems. Wissmar R, 
Steel et al. - Landscapes and juvenile coho salmon

Bisson P (eds). American Fisheries Society: Bethesda, MD: pgs 129-146.

Buffington, J.M., Lisle, T.E., Woodsmith, R.D., and Hilton, S. 2002. Controls on the size and occurrence of pools in coarse-grained forest rivers. River Research and Applications 18:507-531.

Burnett, K.M., Reeves, G.H., Clarke, S., and Christiansen, K. 2006. Comparing riparian and catchment influences on stream habitat in a forested, montane landscape. Am. Fish. Soc. Symp. 48: 175-197.

Burnett, K.M., Reeves, G.H., Miller, D.J., Clarke, S., Vance-Borland, K., and Christiansen, K. 2007. Distribution of salmon-habitat potential relative to landscape characteristics and implications for conservation. Ecological Applications 17: 66-80.

Busch, D.S., Sheer, M., Burnett, K., McElhany, P., and Cooney T. 2013. Landscape-level model to predict spawning habitat for Lower Columbia River fall Chinook Salmon (Oncorhynchus Tshawytscha). River Research and Applications 29: 297-312.

Clarke, S.E., Burnett, K.M., and Miller, D.J. 2008. Modeling Streams and Hydrogeomorphic Attributes in Oregon from Digital and Field Data. J. Am. Water Resour. Assoc. 44(2):459-477.

Daly, C., Neilson, R.P., and Phillips, D.L. 1994. A statistical topographic model for mapping climatological precipitation over mountainous terrain. J. Appl. Meteorol. 33:140-158.

Dolloff, C.A. 1996. Large woody debris, fish habitat, and historical land use. In Proccedings of the Workshop on Coarse Woody Debris in Southern Forests: Effects on Biodiversity Athens, GA October 18-20, 1993, USDA Forest Service General Technical Report SE 
Steel et al. - Landscapes and juvenile coho salmon

748

749

750

751

752

753

754

755

756

757

758

759

760

761

762

763

764

765

766

767
94, pp. 130-138.

Feist, B. E., Steel, E. A., Pess, G.R. and Bilby, R.E. 2003. The influence of scale on salmon habitat restoration priorities. Animal Conservation 6: 271-282.

Firman, J. C., Steel, E. A., Jensen, D.W., Burnett, K.M., Christiansen, K., Feist, B.E., Larsen, D.P., and Anlauf ,K. J. 2011. Landscape models of adult coho salmon density examined at four spatial extents. Trans. Am. Fish. Soc. 140(2): 440-455.

Flitcroft, R. L. 2007. Regions to streams: spatial and temporal variation in stream occupancy patterns of coho salmon (Oncorhynchus kisutch) on the Oregon coast. Doctoral dissertation. Oregon State University, Corvallis, Oregon, USA.

Flitcroft, R.L., Burnett, K.M, Reeves, G.H., and Ganio, L.M. 2012. Do network relationships matter? Comparing network and instream habitat variables to explain densities of juvenile coho salmon (Oncorhynchus kisutch) in mid-coastal Oregon, USA. Aquatic Conservation: Marine and Freshwater Ecosystems 22:288-302.

Flitcroft, R., Burnett, K., Snyder, J., Reeves., G., and Ganio L. 2014. Riverscape patterns among years of juvenile coho salmon. Trans. Am. Fish. Soc. 143:26-38.

Franklin, J.F., and Dyrness, C.T. 1988. Natural Vegetation of Washington and Oregon. Oregon State University Press, Corvallis, Oregon, USA.

Frissell C.A., Liss, W.J., Warren, C.E., and Hurley, M.D. 1986. A hierarchical framework for stream habitat classification. Environ. Manage.10: 199-2.

Gresswell, R. E., Torgersen, C. E., Bateman, D. S., Guy, T. J., Hendricks, S. R., and Wofford, J. 
Steel et al. - Landscapes and juvenile coho salmon

E. B. 2006. Spatially explicit approach for evaluating relationships among coastal cutthroat trout, habitat, and disturbance in small Oregon streams. Amer. Fish. Soc. Sym. 48: $457-471$.

Heifetz, J., Murphy, M.L., and Koski, K.V. 2011. Effects of logging on winter habitat of juvenile salmonids in Alaskan streams. North American Journal of Fisheries Management 6:52-58.

Hicks, B.J., and J.D. Hall. 2003. Rock type and channel gradient structure salmonid populations in the Oregon Coast Range. Trans. Am. Fish. Soc. 132:468-482.

Johnson, L.B., and Host, S.H. 2010. Recent developments in landscape approaches for the study of aquatic ecosystems. Journal of the North American Benthological Society 26: 41-66.

Kahler, T.H., Roni, P., and Quinn, T.P. 2001. Summer movement and growth of juvenile anadromous salmonids in small western Washington streams. Can. J. Fish. Aquat. Sci. 58: $1947-1956$.

Kenward, M.G., and Roger, J.H. 1997. Small sample inference for fixed effects from restricted maximum likelihood. Biometrics 53: 983-997.

Kershner, J.L., Roper, B.B., Bouwes, N., Henderson, R., and Archer, E. 2004. An analysis of stream habitat condition in reference and managed watersheds on some federal lands within the Columbia River Basin. North American Journal of Fisheries Management 24: $1363-1375$.

Larsen, D.P., Kincaid, T.M., Jacobs, S.E., and Urquhart, N.S. 2001. Designs for evaluating local and regional scale trends. Bioscience 51: 1069-1078. 
Steel et al. - Landscapes and juvenile coho salmon

789

790

791

792

793

794

795

796

797

798

799

800

801

802

803

804

805

806

807

808

809

Larsen, D.P., Kaufmann, P.R., Kincaid, T.M., and Urquhart, N.S. 2004. Detecting persistent change in the habitat of salmon-bearing streams in the Pacific Northwest. Can. J. Fish. Aquat. Sci. 61: 283-291.

Lichatowich, J. 1999 Salmon without rivers: a history of the Pacific salmon crisis. Island Press, Washington, D.C.

Logez M,Bady, P., and Pont D. 2012. Modelling the habitat requirement of riverine fish species at the European scale: sensitivity to temperature and precipitation and associated uncertainty. Ecology of Freshwater Fishes 21: 266-282.

Lucero, Y., Steel, E.A., Burnett, K.M., and Christiansen, K.. 2011. Untangling human development and natural gradients: Implications of underlying correlation structure for linking landscapes and riverine ecosystems. River Syst. 19(3): 207-224.

Mellina, E., and Hinch, S.G. 2009. Influences of riparian logging and in-stream large wood removal on pool habitat and salmonid density and biomass: a meta-analysis. Can. J. For. Res. 39: 1280-1301.

Miller, R.R. 2010. Is the past present? Historical splash dam mapping and stream disturbance detection in the Oregon coast range, Corvallis. M.Sc. thesis, Department of Fisheries and Wildlife, Oregon State University, Corvallis, OR, USA..

Montgomery, D.R., Beamer, E.M., Pess, G.R., and Quinn, T.P. 1999. Channel type and salmonid spawning distribution and abundance. Can. J. Fish. Aquat. Sci.56: 377-387.

Moore K.M.S., Jones, K.K., and Dambacher, J.M. 2007. Methods for stream habitat surveys: Aquatic Inventories Project. Oregon Department of Fish and Wildlife Information 
Steel et al. - Landscapes and juvenile coho salmon

Report, Salem, Oregon.

Nakagawa, S., and Schielzeth, H. 2013. A general and simple method for obtaining $R 2$ from generalized linear mixed-effects models. Methods in Ecology and Evolution 4: 133-142.

Nickelson T.E., Rodgers J.D., Johnson S.L., and Solazzi M.F. 1992. Seasonal changes in habitat use by juvenile coho salmon (Oncorhynchus kisutch) in Oregon coastal streams. Can. J. Fish. Aquat. Sci. 49: 783-789.

Ohmann, J. L., and Gregory, M. J. 2002. Predictive mapping of forest composition and structure with direct gradient analysis and nearest-neighbor imputation in coastal Oregon, USA. Can. J. For. Res. 32: 725-741.

Oregon Department of Forestry. 2004. 1:24 000-scale land ownership in Oregon. Oregon Department of Forestry, Salem, Oregon, USA. Available from http://www.oregon.gov/DAS/CIO/GEO/pages/alphalist.aspx\#1 [accessed 19 November 2015].

Pess, G.R., Montgomery, D.R., Steel, E.A., Bilby, R.E., Feist, B.E., and Greenberg, H.M. 2002. Landscape characteristics, land use, and Coho salmon (Oncorhynchus kisutch) abundance, Snohomish River, Washington, USA. Can. J. Fish. Aquat. Sci. 59: 613-623.

Sandercock, F.K. 1991. Life history of coho salmon (Oncorhynchus kisutch). In Pacific Salmon Life Histories. Edited by C. Groot and L. Margolis. UBC Press, Vancouver, Canada, pp. 397-445.

Sedell, J.R., and Duval, S.. 1985. Influence of forest and rangeland management on anadromous fish habitat in western North America: Water transportation and storage of logs. USDA 
Steel et al. - Landscapes and juvenile coho salmon

United States Forest Service General Technical Report GTR-PNW-186, Pacific Northwest Research Station, Portland, OR. 68 p.

Solazzi, M.F., Nickelson, T.E., Johnson, S.L., and Rodgers, J.D. 2000. Effects of increasing winter rearing habitat on abundance of salmonids in two coastal Oregon streams. Can. J. Fish. Aquat. Sci. 57(5): 906-914.

Spies, T.A., Johnson, K.N., Burnett, K.M., Ohmann, J.L., McComb, B.C., Reeves, G.H., Bettinger, P., Kline, J.D., and Yonts, B.G. 2007. Cumulative ecological and socioeconomic effects of forest policies in coastal Oregon. Ecological Applications 17: 5-17.

Steel, E.A., Feist, B.E., Jensen, D.W., Pess, G.R., Sheer, M.B., Brauner, J.B., and Bilby, R.E. 2004. Landscape models to understand Steelhead (Oncorhynchus mykiss) distribution and help prioritize barrier removals in the Willamette Basin, Oregon, USA. Can. J. Fish. Aquat. Sci. 61: 999-1011.

Steel, E.A., Hughes, R.M., Fullerton, A.H., Schmutz, S., Young, J.A., Fukushima, M., Muhar, S., Poppe, M., Feist, B.E., and Trautwein, C. 2010. Are we meeting the challenges of landscape-scale riverine research? A review. Living Reviews in Landscape Research 4. Available from http://lrlr.landscapeonline.de [accessed 19 November 2015]

Steel, E.A., Jensen, D.W., Burnett, K.M., Christiansen, K., Firman, J.C., Feist, B.E., Anlauf, K., and Larsen, D.P. 2012. Landscape characteristics and coho salmon (Oncorhynchus kisutch) distributions: explaining abundance versus occupancy. Can. J. Fish. Aquat. Sci. 69: 457-468. 
Steel et al. - Landscapes and juvenile coho salmon

852 Stevens, D.L. 2002. Sampling design and statistical analysis methods for the integrated

853

854

855

856

857

858

859

860

861

862

863

864

865

866

867

868

biological and physical monitoring of Oregon streams. Oregon State University, OPSWODFW-2002-07, Corvallis, Oregon, USA.

USDA Forest Service.1990. Land and resource plan for the Siuslaw National Forest, Siuslaw National Forest, Corvallis. Available from http://www.fs.usda.gov/Internet/FSE_DOCUMENTS/fsbdev7_007057.pdf [accessed 19 November 2015].

Walker, G.W., MacLeod, N.S., Miller, R.J., Raines, G.L., and Connors, K.A. 2003. Spatial digital database for the geologic map of Oregon. U.S. Geological Survey, Open-File Report 03-67, Menlo Park, California.

Weitkamp, L.A., Wainwright, T.C., Bryant, G.J., Milner, G.B., Teel, D.J., Kope, R.G., and Waples, R.S. 1995. Status review of Coho salmon from Washington, Oregon, and California. U.S. Dept. Commerce, NOAA Tech. Memo. NMFS-NWFSC-24. Available from http://www.nwfsc.noaa.gov/assets/25/5585_06172004_123333_coho.pdf [accessed 19 November 2015]

Wohl, E.E., K.R. Vincent, D.J. Merritts. 1993. Pool and riffle characteristics in relation to channel gradient. Geomorphology 6(2): 99-110. 
Steel et al. - Landscapes and juvenile coho salmon

869 Table 1. Geospatial data layers and variables extracted for use in exploratory analysis, base

870 models, and hypothesis testing.

\begin{tabular}{|c|c|c|}
\hline $\begin{array}{l}\text { Geospatial } \\
\text { Datalayer }\end{array}$ & $\begin{array}{l}\text { Map Scale } \\
\text { Gridcell Size }\end{array}$ & Variable \\
\hline $\begin{array}{l}\text { Modeled Air Temperature: Ambient air } \\
\text { temperatures (1961 - 1990) expressed as } \\
\text { means over the subtypes described in } \\
\text { Precipitation Elevation Regressions on } \\
\text { Independent Slopes Model (PRISM) (Daly } \\
\text { et al. 1994). Variables calculated as an } \\
\text { area-weighted mean across grid cells } \\
\text { within the catchment area. }\end{array}$ & N/A & $\begin{array}{l}\text { MaxAirTemp: maximum annual temperature } \\
\left({ }^{\circ} \mathrm{C}\right) . \\
\text { TempRange: annual temperature range }\left({ }^{\circ} \mathrm{C}\right) .\end{array}$ \\
\hline $\begin{array}{l}\text { Modeled Precipitation: Cumulative mean } \\
\text { annual precipitation (1961 - 1990), from } \\
\text { Precipitation Elevation Regressions on } \\
\text { Independent Slopes Model (PRISM) (Daly } \\
\text { et al. 1994). Calculated as area-weighted } \\
\text { mean across grid cells within the }\end{array}$ & N/A & Precip: mean annual precipitation (mm). \\
\hline
\end{tabular}


Steel et al. - Landscapes and juvenile coho salmon

\begin{tabular}{|c|c|c|}
\hline catchment area. & & \\
\hline $\begin{array}{l}\text { Geology: Classification of geologic map } \\
\text { units according to major lithology (Walker } \\
\text { et al. 2003). }\end{array}$ & - & $\begin{array}{l}\text { Landslide: Proportion of watershed with an } \\
\text { estimated delivery weighted landslide density } \\
\text { above } 2.3 \text { landslides/kmsq. } \\
\text { Sedimentary: Proportion of watershed } \\
\text { classified as sedimentary geology. }\end{array}$ \\
\hline $\begin{array}{l}\text { Land Ownership: Land ownership } \\
\text { classification (Oregon Department of } \\
\text { Forestry 2004). }\end{array}$ & $1: 24 \mathrm{k}$ & $\begin{array}{l}\text { BLM: Proportion of watershed owned by U.S. } \\
\text { Bureau of Land Management. } \\
\underline{\text { USFS: Proportion of watershed owned by }} \\
\text { U.S. Forest Service. } \\
\text { Public: BLM + USFS + proportion of } \\
\text { watershed owned by State of Oregon. } \\
\text { PrivateInd: Proportion of watershed that is } \\
\text { private industrial forest and all other private } \\
\text { lands. } \\
\text { PrivateNI: Proportion of watershed that is } \\
\text { private non-industrial forest. }\end{array}$ \\
\hline $\begin{array}{l}\text { Tree Size and Type: Predictive mapping of } \\
\text { forest composition using direct gradient } \\
\text { analysis and nearest neighbor imputation } \\
\text { (Ohmann and Gregory, 2002). }\end{array}$ & $25 \mathrm{~m}$ & $\begin{array}{l}\text { BigTrees: Proportion of watershed estimated } \\
\text { to be in the following classes: Conifers }(50-75 \\
\mathrm{cm})+ \text { Very Large Conifers }(>75 \mathrm{~cm})+\text { Large } \\
\text { Mixed }(50-75 \mathrm{~cm})+\text { Very Large Mixed }(>75 \\
\mathrm{cm}) \text {. }\end{array}$ \\
\hline
\end{tabular}


Steel et al. - Landscapes and juvenile coho salmon

\begin{tabular}{|c|c|c|}
\hline & & $\begin{array}{l}\text { VLConifers: Proportion of watershed } \\
\text { estimated to be in Very Large Conifers ( }>75 \\
\mathrm{~cm}) \text {. }\end{array}$ \\
\hline $\begin{array}{l}\text { Digital elevation model (DEM): USGS } 10 \\
\text { m DEM. }\end{array}$ & NA & $\begin{array}{l}\text { DrainageArea: Total area upslope of the } \\
\text { downstream end of any given index reach. } \\
\text { Generated from a USGS } 10 \mathrm{~m} \operatorname{DEM}\left(\mathrm{m}^{2}\right) \text {. } \\
\text { Gradient: Change in elevation (upstream } \\
\text { elevation minus downstream elevation) } \\
\text { divided by length of the reach (\%). } \\
\text { Elevation: Elevation of downstream terminus } \\
\text { of reach, as measured from } 10 \mathrm{~m} \mathrm{DEM} \mathrm{(m).}\end{array}$ \\
\hline $\begin{array}{l}\text { Intrinsic Potential: Predicted total area of } \\
\text { instream rearing habitat for juvenile Coho } \\
\text { salmon (O. kisutch) based on the } \\
\text { geometric mean of normalized values for } \\
\text { flow, gradient, and valley constraint } \\
\text { (Burnett et al. 2007; Clarke et al. 2008). }\end{array}$ & $1: 24 \mathrm{k}$ & $\begin{array}{l}\text { AvgIP: Average value of intrinsic potential } \\
\text { for the reach (unitless). } \\
\text { LengthHighIP: Total length of stream with } \\
\text { intrinsic potential }>0.75 \text { in catchment } \\
\text { (unitless). }\end{array}$ \\
\hline $\begin{array}{l}\text { Historical Stream Disturbances: Historical } \\
\text { archives were used to create a geodatabase } \\
\text { of historical splash-dam and log-drive } \\
\text { sites in Western Oregon (Miller 2010) }\end{array}$ & ----------- & $\begin{array}{l}\text { SplashDams: Presence of historical splash } \\
\text { dams (count). } \\
\text { LogDrive: Length of historical log drives } \\
\text { within the catchment area (m). }\end{array}$ \\
\hline
\end{tabular}

871 
Steel et al. - Landscapes and juvenile coho salmon

872 Table 2. Linear model estimating $\ln$ (pool surface area) using immutable variables from Anlauf et

873 al. (2011).

\begin{tabular}{ccccc}
\hline Predictor variable & Unit $^{\dagger}$ & Coefficient $^{\dagger \dagger}$ & Lower 95\% CI & Upper 95\% CI \\
\hline Gradient & 0.016 & -0.251 & -0.322 & -0.181 \\
Elevation & 65.427 & 0.062 & 0.014 & 0.110 \\
Ln (Drainage area) & 0.558 & 0.412 & 0.358 & 0.465 \\
Survey length & 133.200 & 0.196 & 0.143 & 0.250 \\
Sedimentary & 0.100 & -0.010 & -0.038 & 0.018
\end{tabular}

$874{ }^{\dagger}$ The unit column describes approximately $1 / 10^{\text {th }}$ of the observed range of the predictor variable.

$875{ }^{\dagger}$ The coefficients describe the effect of a 1-unit change in the predictor variable on the log scale 876 response. $\mathrm{CI}=$ confidence interval

877 
Steel et al. - Landscapes and juvenile coho salmon

878 Table 3, The Poisson model (log link) for juvenile coho salmon counts using immutable

879 variables from Anlauf et al. (2011).

\begin{tabular}{|c|c|c|c|c|}
\hline \multirow{3}{*}{ Predictor variable } & \multirow{3}{*}{ Unit $^{\dagger}$} & \multirow{3}{*}{ Coefficient $^{\dagger \dagger}$} & Lower 95\% & Upper 95\% \\
\hline & & & Confidence & Confidence \\
\hline & & & Interval & Interval \\
\hline Precip & 292.553 & -0.114 & -0.257 & 0.029 \\
\hline Sedimentary & 0.100 & 0.091 & -0.005 & 0.186 \\
\hline Gradient & 0.016 & -0.211 & -0.399 & -0.023 \\
\hline Gradient $^{2}$ & 0.016 & -0.074 & -0.147 & -0.001 \\
\hline Elevation & 65.427 & 0.011 & -0.122 & 0.143 \\
\hline Drainage area & 16.919 & -0.382 & -0.545 & -0.218 \\
\hline
\end{tabular}

The unit column describes approximately $1 / 10^{\text {th }}$ of the observed range of the predictor variable.

$881{ }^{\dagger}$ The coefficients describe the effect of a 1-unit change in the predictor variable on the log-scale 882 response. 
Steel et al. - Landscapes and juvenile coho salmon

885 Table 4. Hypothesis tests for key variables of interest in which p-values describe 1 degree of 886 freedom chi-square tests (GLMM) or Kenward-Roger F tests (LMM) for the addition of a key 887 variable of interest to a model that already contains immutable variables (see Table 2 for base 888 pool model and Table 3 for base juvenile coho salmon model).

\begin{tabular}{|c|c|c|c|c|c|c|c|}
\hline \multirow[b]{2}{*}{ Variable } & \multirow[b]{2}{*}{ Unit $^{\dagger}$} & \multicolumn{3}{|c|}{ Pool Surface Area } & \multicolumn{3}{|c|}{ Juvenile coho salmon } \\
\hline & & P-value & Effect $^{\dagger \dagger}$ & $95 \% \mathrm{CI}$ & P-value & Effect $^{\dagger \dagger}$ & $95 \% \mathrm{CI}$ \\
\hline $\begin{array}{c}\text { AvgIP } \\
\text { (full model) }\end{array}$ & 0.1 & 0.093 & $-5.2 \%$ & $(-10.9,0.9)$ & 0.567 & $-5.6 \%$ & $(-22.4,14.9)$ \\
\hline $\begin{array}{c}\text { AvgIP } \\
\text { (w/out grad.) }\end{array}$ & 0.1 & $<0.0001$ & $9.2 \%$ & $(4.8,13.7)$ & $\begin{array}{c}<0.000 \\
1\end{array}$ & $30.7 \%$ & $(19.2,44.2)$ \\
\hline LengthHighIP (m) & 2641 & $<0.0001$ & $-10.5 \%$ & $(-14.8,-6.0)$ & 0.828 & $-1.5 \%$ & $(-14.5,13.4)$ \\
\hline Public & 0.1 & $<0.0001$ & $7.7 \%$ & $(4.8,10.8)$ & 0.827 & $0.9 \%$ & $(-7,9.5)$ \\
\hline PrivateInd & 0.1 & $<0.0001^{*}$ & $-6.1 \%$ & $(-8.8,-3.3)$ & $0.972^{*}$ & $-0.2 \%$ & $(-8.8,9.1)$ \\
\hline PrivateNI & 0.1 & $<0.0001^{*}$ & $-15.6 \%$ & $(-20.9,-9.9)$ & $0.972^{*}$ & $-2.4 \%$ & $(-20.1,19.1)$ \\
\hline SplashDams $^{* *}$ & + & 0.514 & $11.4 \%$ & $(-19.2,53.5)$ & 0.049 & $139.5 \%$ & $(0.4,474.9)$ \\
\hline LogDrive (m) & 0.0001 & 0.109 & $-3.5 \%$ & $(-7.6,0.7)$ & 0.466 & $-4.4 \%$ & $(-15.5,8.0)$ \\
\hline \multicolumn{8}{|c|}{ The unit column describes approximately $1 / 10^{\text {th }}$ of the observed range of the predictor variable. } \\
\hline \multicolumn{8}{|c|}{ indicates the percent increase and a negative number indicates a percent reduction. } \\
\hline \multicolumn{8}{|c|}{${ }^{*}$ Tests for private ownership were conducted by adding private industrial and private non- } \\
\hline industrial to the im & atable $n$ & del simult & eously. & he two p-val & therefo & reflec & chi- \\
\hline
\end{tabular}


Steel et al. - Landscapes and juvenile coho salmon

$895^{* *}$ The plus symbol for the unit size of splash dams indicates that this effect is for presence versus 896 absence of any splash dams in the watershed draining to the study reach. 
Steel et al. - Landscapes and juvenile coho salmon

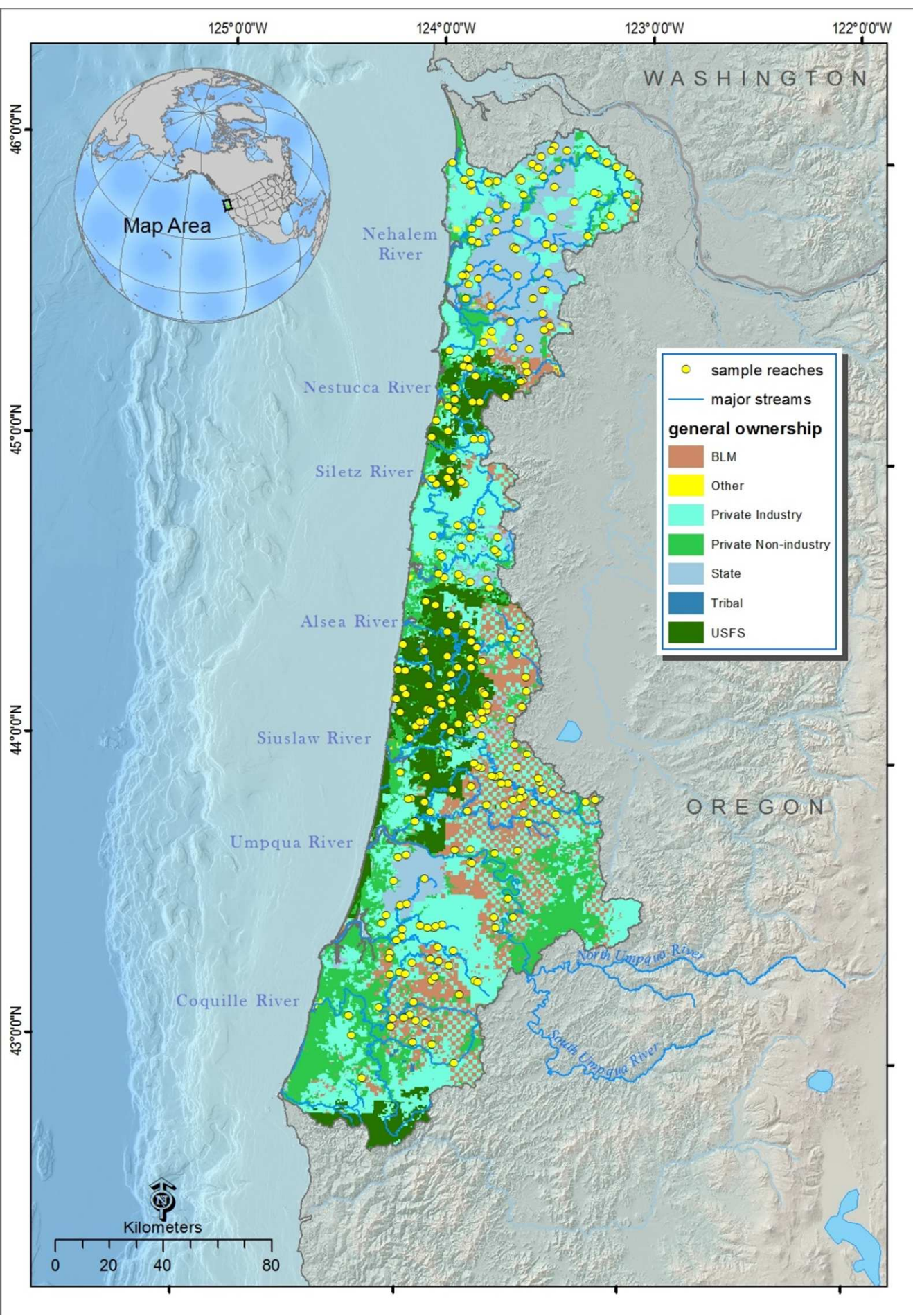

898 Fig. 1. Map of the Oregon Coast, USA with study reaches identified by points and land 899 ownership (Table 1; Oregon Department of Forestry 2004). 
Steel et al. - Landscapes and juvenile coho salmon
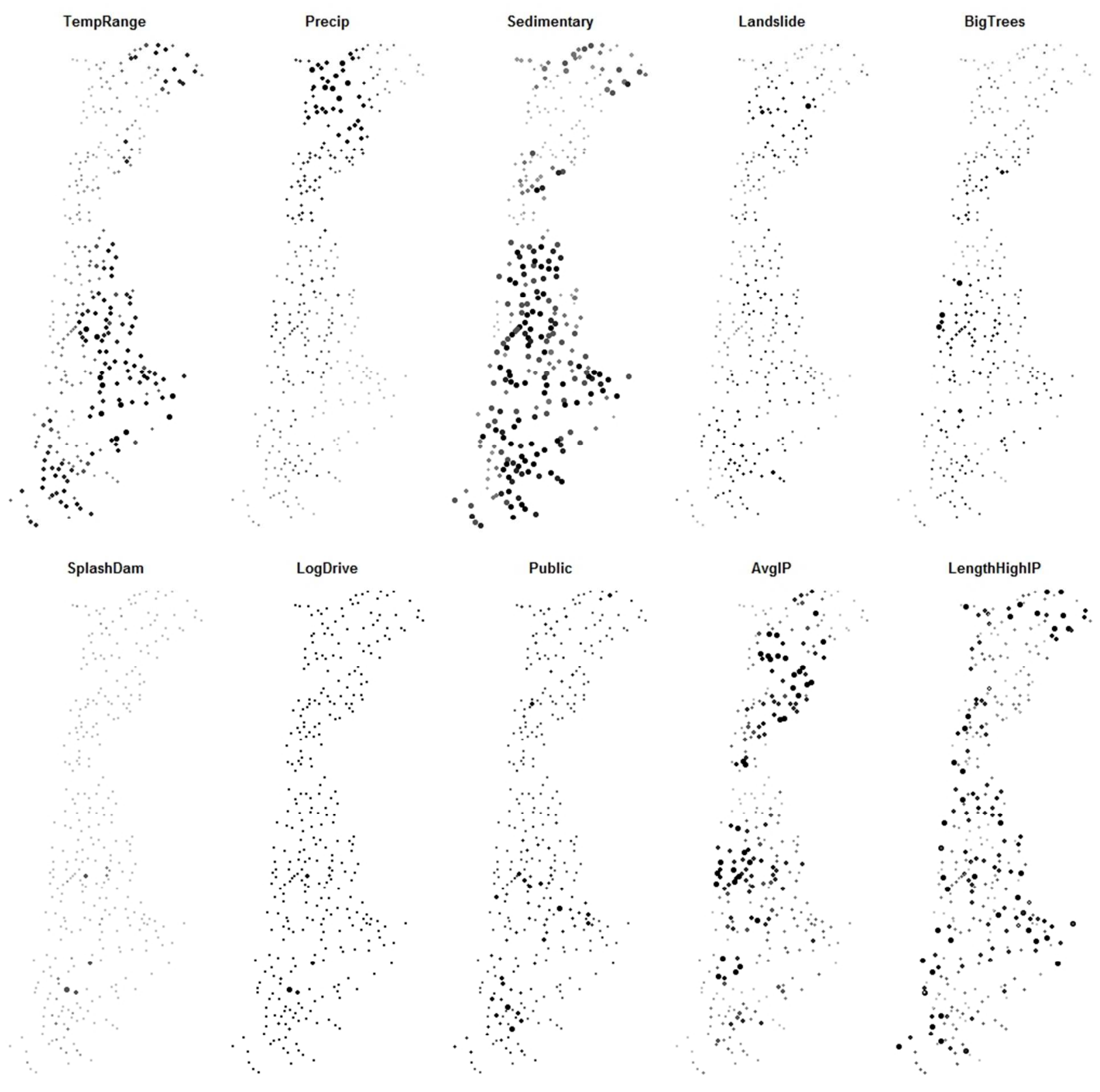

901 Fig. 2. Spatial distribution of a set of potential landscape-scale predictor across the Oregon

902 Coast study area. For variable definitions see Table 1. 
Steel et al. - Landscapes and juvenile coho salmon
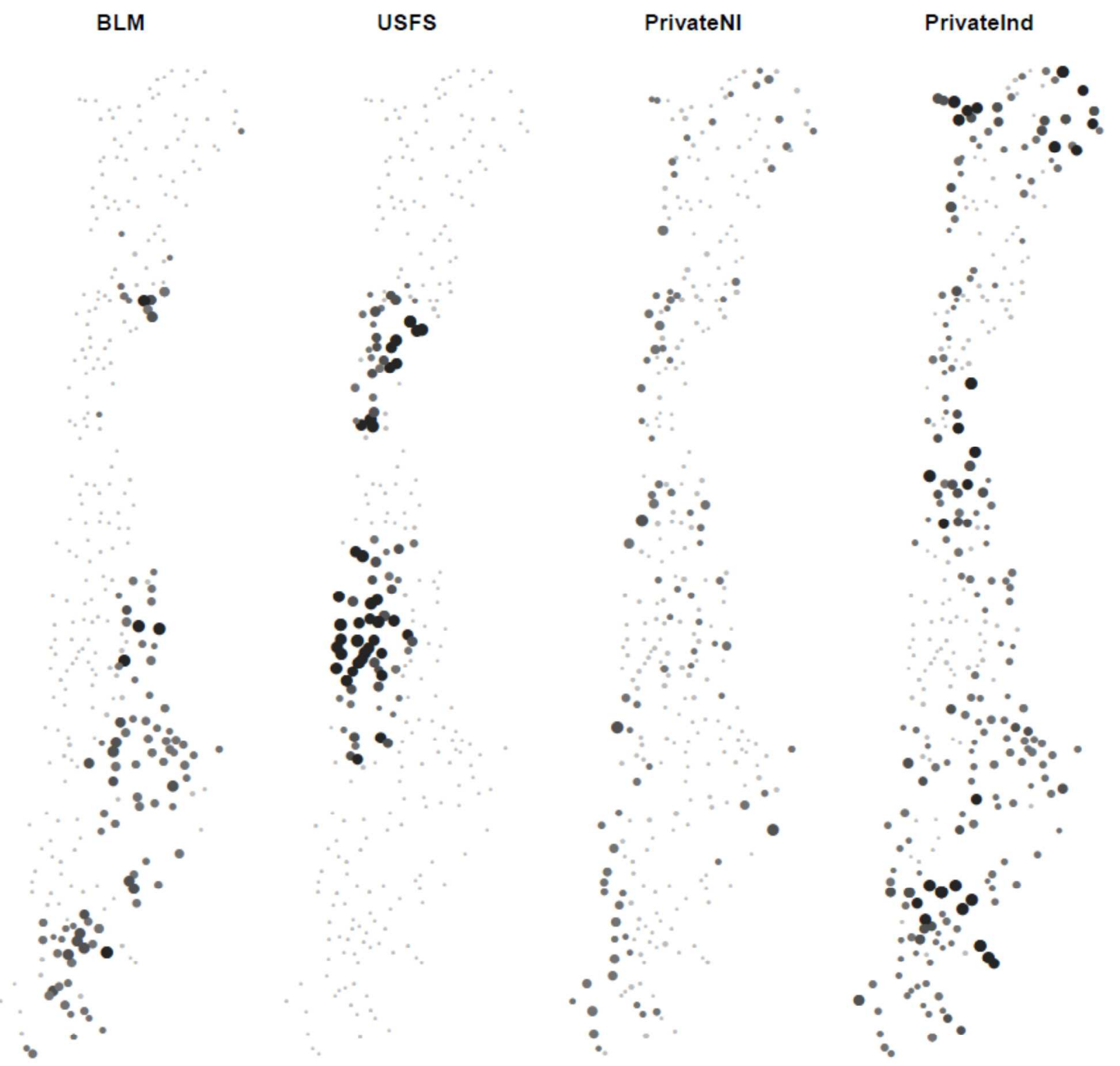

Fig. 3. Spatial distribution of landownership across the study watersheds. PrivateNI $=$ Private non-industrial forest lands. PrivateInd = private industrial forests. 
Steel et al. - Landscapes and juvenile coho salmon
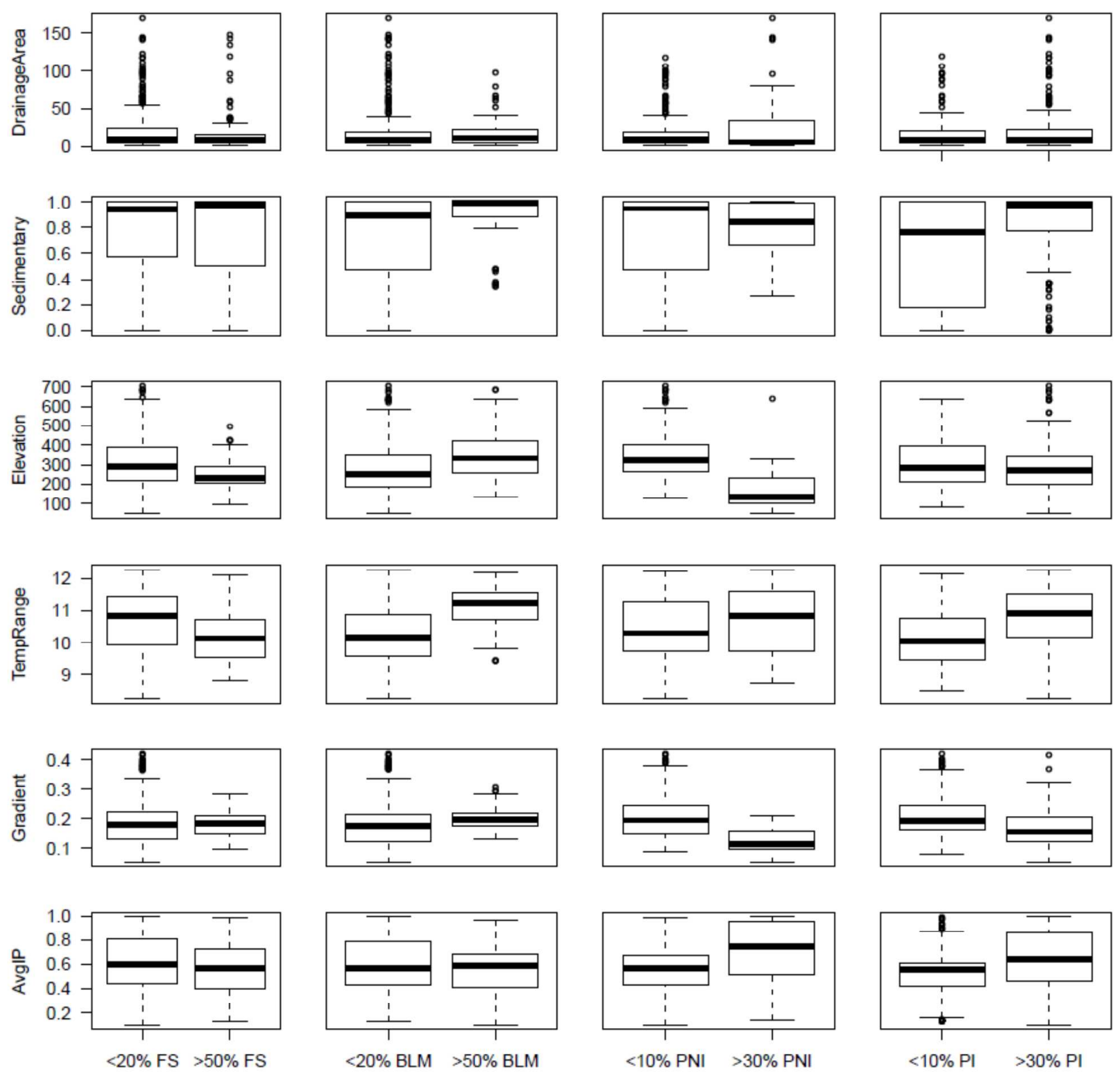

908 Fig. 4. Comparison of landscape attributes for sites that have relatively more of a particular

909 ownership classification versus relatively less. The exact cut-offs differ between the two private

910 and the two public ownership categories in order to provide a reasonable sample size in both

911 categories. $\mathrm{PI}=$ Private industrial $($ PrivateInd); PNI $=$ Private non-industrial $($ PrivateNI). 
Steel et al. - Landscapes and juvenile coho salmon
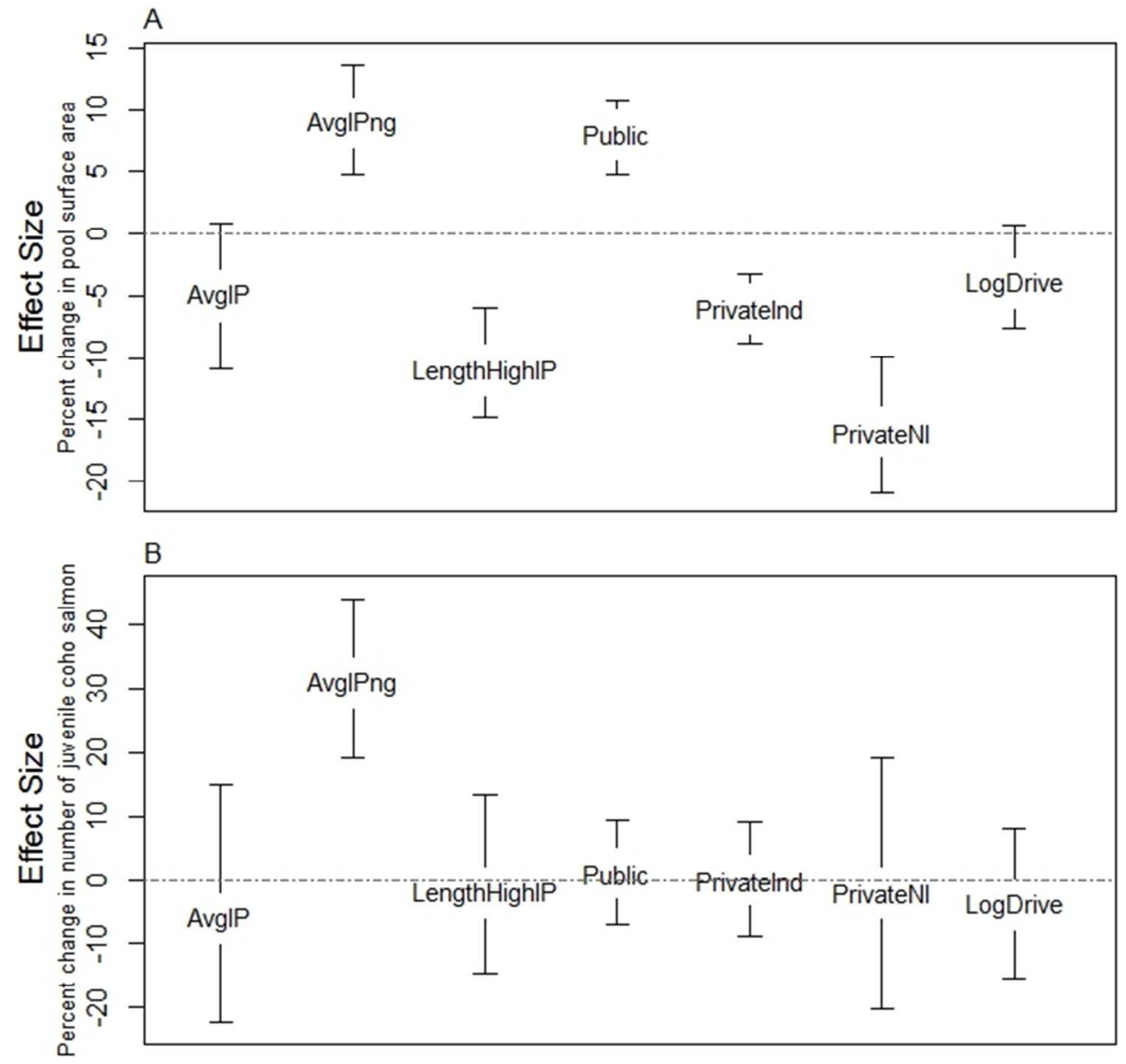

913 Fig. 5. Effect sizes for key variables when entered in to either (a) the pool surface area model or (b) the model for number of juvenile coho salmon. In each case the unit of the effect is approximately $1 / 10^{\text {th }}$ of the observed range of that variable within our data (See Table 4). Note

916 that Average Intrinsic Potential is tested in two ways: once on the full immutable model (AvgIP)

917 and once on the immutable without gradient (AvgIPng). The effect of the length of stream with

918 high intrinsic potential in the watershed draining to the reach (LengthHighIP) is statistically

919 significant in the pool surface model but not in the number of juvenile coho salmon model.

920 Splash dams were not included in the Fig. because there was no equivalent effect of $1 / 10^{\text {th }}$ of the 921 observed range of the data for presence/absence of splash dams. 
Steel et al. - Landscapes and juvenile coho salmon
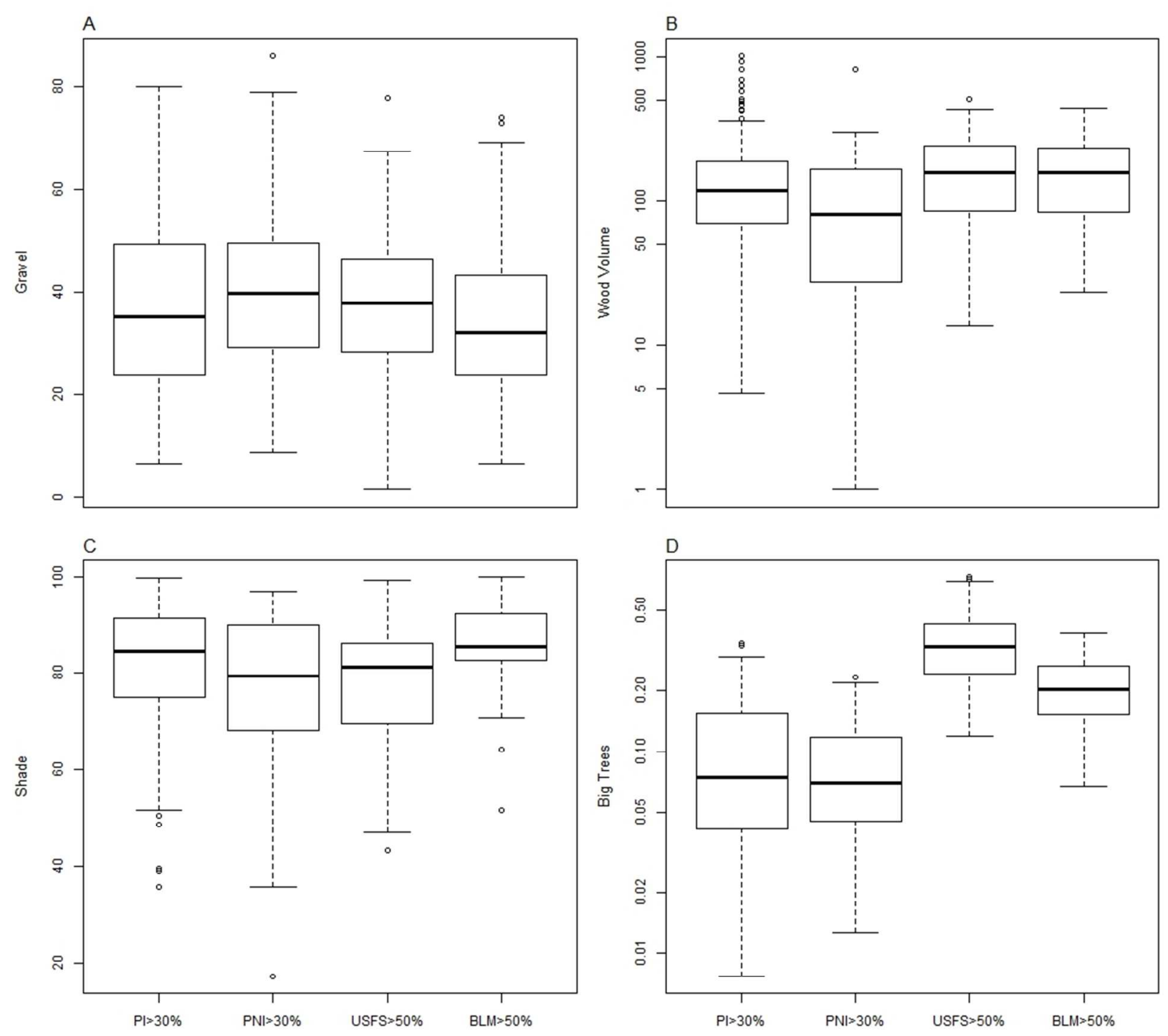

922

923 Fig. 6. The distribution of (A-C) instream habitat variables associated with high quality juvenile

924 coho habitat as a function of land ownership and (D) percent of the watershed with big trees

925 (Table 1). Gravel is the proportion of the stream-bed area that is classified as gravel (2-64 $\mathrm{mm})$.

926 Wood volume is the volume of in-stream wood per $100 \mathrm{~m}$ of reach length $\left(\mathrm{m}^{3}\right.$ per $\left.100 \mathrm{~m}\right)$.

927 Percent shade is the percentage of the stream channel that is shaded. PI = Private industrial

928 (PrivateInd); PNI = Private non-industrial $($ PrivateNI) 